\title{
Vitamin characterization and volatile composition of camu-camu (Myrciaria dubia (HBK) McVaugh, Myrtaceae) at different maturation stages
}

\author{
Francisca das Chagas do Amaral SOUZA ${ }^{1}$, Edson Pablo SILVA ${ }^{2 *}$ (D), Jaime Paiva Lopes AGUIAR ${ }^{1 *}$
}

\begin{abstract}
During the process of fruit development there is synthesis and catabolism of compounds that culminate with the specific characteristics of each species, such as changes in color, size, acidity, vitamins content and volatile composition. In the present study was evaluated during the development of camu-camu (Myrciaria dubia (HBK) McVaugh, Myrtaceae) the contents of pH, At, SS ( ${ }^{\circ}$ Brix), Vitamin C, polyphenols, $\left(\mathrm{L}^{*}, \mathrm{a}^{*}\right.$ and $\mathrm{b}^{*}$ ) coloration and volatile composition using the HSPME-CGMS technique, at different stages of development. During development, an increase in the ${ }^{\circ}$ brix variable was detected (6.92 to 9.02), and a decrease in the levels of vitamin C $1150 \mathrm{mg} / 100 \mathrm{~g}$ and total polyphenols 1280mg / 100g. Regarding the volatile composition, there was a difference of compounds according to the stage of development analyzed. Among the identified components, terpenes were the major class of compounds at all stages of maturation $(\mathrm{p}<0.05)$.
\end{abstract}

Keywords: CG/MS; volatile; maturation; food analysis; exotic fruits.

Practical Applications: Amazon fruits are an important source of nutrients acting in human metabolism, with a big interest in the chemical, food, and pharmaceutical industries. The camu camu presented a high value for vitamins and the characteristics of a volatil composition rich in terpene compounds.

\section{Introduction}

Natural volatile compounds include various chemical substances, such as esters, lactones, alcohols, acids, aldehydes, ketones, hydrocarbons, and some phenols, ethers, and heterocyclic compounds. These chemical substances play vital roles throughout a plant's life cycle by facilitating interactions with the environment in which they live. The substances, which are produced by plants for various reasons, form part of their immune system and determine the characteristic aroma of each plant (Janzantti et al., 2012; Simões, 2003). Aldehydes, alcohols, esters, and acids, which are important groups for the aromatic characteristics of various fruits, are likely formed via a lipid metabolism pathway (Knee, 2002).

Camu-camu (Myrciaria dubia (HBK) McVaugh, Myrtaceae), a typical Amazonian fruit tree, is naturally found on the banks of rivers, lakes, and igapós, both in dark and clear waters. These fruits have an agreeable appearance and taste (Yuyama et al., 2002). Camu-camu has high nutritional value because of the high vitamin C (1380-1490 mg/100 g pulp and $2050 \mathrm{mg} / 100 \mathrm{~g}$ peel) and potassium content in this fruit, in addition to the presence of carotenoids, such as anthocyanins (Zanatta \& Mercadante 2007). However, although these substances have important physiological functions, such as mediating interactions between other plants and defending against microorganisms, they can also be volatile, because many of these substances are monoterpenes (Pontes et al., 2009; Aguiar et al., 2019). There are no studies related to the volatile composition of these substances. Some volatile compounds, such as d-limonene, can treat sputum and have anticancer activity. B-Linalool is used to treat a variety of diseases and has anti-inflammatory properties, while (E)- $\alpha$-bergamotene and (E)- $\beta$-farnesene indirectly defend the plants against lepidopteran larvae (Rodríguez et al., 2011). The analysis of the volatile compounds is of extreme importance for the characterization of new genetic materials, because the identification of these allows the discovery of new compounds that can be used in the food industry. Additionally, studying the formation or changes of the volatile compound composition during the maturation, processing, and storage of the fruits and their products can increase the understanding of how flavor is formed (Cozzolino et al., 2001). Moreover, the aroma is one of the most expressive characteristics of a food, and the characterization of the aromatic profile can represent a useful tool to evaluate the organoleptic properties, as well as can be used to guarantee the authenticity of the fruit (Janzantti et al., 2012). In the early 1990s, headspace solid-phase microextraction (HSPME) emerged as a promising alternative for conventional techniques in the isolation of headspace volatile compounds (Ma et al., 2013).

HSPME, which combines the extraction and preconcentration in a single step, is one of the most modern techniques used for extraction. It has many advantages, such as high sensitivity, low-cost, solventless, and simplicity, over the conventional extraction techniques (Ma et al., 2013; Pontes et al., 2009). Because of the high sensitivity of this assay, it can be used to identify the volatile fruit profile, especially in fruits without a present study on their volatile composition. In this study, we 
determine the chemical and volatile composition of camu-camu (Myrciaria dubia (H.B.K.) McVaugh, Myrtaceae) in CG / MS at different stages of development using HSPME.

\section{Material and methods}

\subsection{Plant material and evaluation of fruit}

Fruits were harvested at random in the morning from January 2019 to March 2019 at the INPA (National Institute for Research in the Amazon) Campus in Manaus, Brazil (latitude $3^{\circ} 092$ ' 820 “S, 59994 '046” O longitude). The fruits were divided into three equal batches according to the stages of development immature green, mature green and ripened representing the fruits of the day. The fruits were frozen in liquid nitrogen and stored in a freezer until the time of analysis.

\subsubsection{Chemical characterization}

Total soluble solids (TSS) of the pulp were measured with a digital refractometer 'Palette' PR-100 (ATAGO U.S.A., Inc.), with an automatic temperature compensation at $25{ }^{\circ} \mathrm{C}$ (Association of Official Agricultural Chemists, 2010) and the results were expressed as ${ }^{\circ} \mathrm{Brix}$. The results for titratable acidity were expressed as $100 \mathrm{~g}-1$ pulp in natura, considering citric acid as the predominant acid, during the development stages. The $\mathrm{pH}$ of the pulp was measured with a $\mathrm{pH}$ meter, Tec-3P-MP (TECNAL - Sao Paulo, Brazil) according to the methods described Association of Official Agricultural Chemists (2010). All the experiments were repeated 6 times independently. Colour of the peel $\left(L^{*}, a^{*}, b^{*}\right)$ was determined at different points using a colour measuring spectrophotometer (HunterLab ColorQUEST II Sphere) - Sao Paulo, Brazil.

\subsubsection{Total polyphenols}

The content were reference measured by a photometric Folin-Ciocalteu assay according to a proposed international standard method (Association of Official Agricultural Chemists, 2010). Absorbance (E) at $540 \mathrm{~nm}$ of the reaction solution is determined in a $1 \mathrm{~cm}$ light-path cell by a Lengguang-752 spectrophotometer (Shimadzu Optical Instrument Sao Paulo, Brazil). The calibration standard is gallic acid.

\subsubsection{Vitamin C}

L-Ascorbic acid (vitamin C) and metaphosphoric acid were purchased from Merck (A Coruña, Spain). All analyses were carried out in duplicate on tissue vegetable homogenized using a pestle and mortar. The vitamin $\mathrm{C}$ was extracted as described by Association of Official Agricultural Chemists (2010). Twenty grams of homogenate was mechanically stirred in $60 \mathrm{ml}$ of a 4É $5 \%$ $(\mathrm{w} / \mathrm{v})$ solution of metaphosphoric acid for $15 \mathrm{~min}$. The mixture was filtered (Whatman No 541), and the was diluted to $100 \mathrm{ml}$ with HPLC grade water. An aliquot of the acid extract was then filtered through $0.45 \mu \mathrm{m}$ Millipore filter prior to injection into the chromatographic column. The HPLC apparatus used consisted of a Spectra-Physics liquid chromatograph equipped with anSP8800 ternary pump and a Rheodyne $20 \mu \mathrm{L}$ injection loop and a Spectra Focus UVÈVis forward optical scanning detector controlled by Spectra Focus software. The column was a Tracer ODS2 C18 column (4 id x250 mm) of particle size $5 \mu \mathrm{m}$ (Tecknocromc,Vigo, Spain); and was used with a precolumn (Tecknocromc TR-015326) packed with the same material. The mobile phase was HPLC grade water brought to $\mathrm{pH} 2.2$ with metaphosphoric acid; the flow rate was $0.5 \mathrm{ml} \cdot \mathrm{min}^{-1}$, the detection wavelength was $245 \mathrm{~nm}$. Quantitation used the external standard method. This method was developed in our laboratory and it is described in detail (including repeatability, recovery and limit of detection) in a previous paper Association of Official Agricultural Chemists (2010).

\subsection{Volatile compounds}

\subsubsection{Fiber conditioning and extraction of volatile compounds}

Volatile compounds were extracted by the HS-SPME technique. Pulp (sample, $1 \mathrm{~g}$ ) was transferred to a $10 \mathrm{~mL}$ glass vial (suitable for volatile retention) which was continuously stirred at $50{ }^{\circ} \mathrm{C}$ for $15 \mathrm{~min}$. The 50/30 $\mu \mathrm{m} \mathrm{DVB/CAR/PDMS}$ fibre (divinylbenzene/carboxen/polydimethylsiloxane) (Supelco, Bellefonte, PA, USA) was used to separate the volatile compounds present in the sample. The fibre was packed at a temperature of $270{ }^{\circ} \mathrm{C}$ for $1 \mathrm{~h}$ prior to use. The pre-conditioning time for the analytes was $25 \mathrm{~min}$. The fibre was exposed to the headspace of glass vial containing the sample at $50^{\circ} \mathrm{C}$ for $15 \mathrm{~min}$, the syringe was immediately taken to the CG-MS injector, wherein, the volatile compounds were desorbed at $250^{\circ} \mathrm{C}$ for 2 min resulting in a splitless injection.

A spectrometer, CGMS-2010 Plus (Shimadzu) Tokyo, Japan with a mass selective detector model QP2010 Plus was used to detect the volatile compounds. A capillary column of fused silica ( $30 \mathrm{~m} \times 0.25 \mathrm{~mm}$ and $0.25 \mu \mathrm{m}$ thick) with $5 \%$ of diphenyl-, 95\% polydimethylsiloxane polymer (DB5) acting as a stationary phase. For best separation, temperature gradient was established in the column initiating from $60^{\circ} \mathrm{C}$, with an increase of $3{ }^{\circ} \mathrm{C}$ per min until the maximum temperature of $270^{\circ} \mathrm{C}$ was attained. The carrier gas was helium and the flow rate was adjusted to $1.8 \mathrm{~mL} \mathrm{~min}{ }^{-1}$ for splitless injection with initial pressure of $100 \mathrm{KPa}$ in the column. The conditions adjusted in the mass spectrometer (MS) were: mass selective detector operating by electronic impact and impact energy of $70 \mathrm{eV}$; scanning speed of $1000 \mathrm{~m} / \mathrm{z} \mathrm{s}^{-1}$; scan interval of 0.5 fragments/ sec and filter for mass of the detected fragments being $29 \mathrm{Da}$ and $600 \mathrm{Da}$. Each component was identified by comparing its mass spectra with already existing information present in the spectrometer databases (Willey229.lib and FFSC1.3.Lib) and the component identification book by Adams (2007). For comparing and calculating the indices, standards of the saturated alkanes (C7-C30) (Supelco, Sigma-Aldrich, Bellefonte, PA, USA) were used as a reference to determine the retention index (RI).

\subsection{Statistical analysis}

Statistical analysis of the chemical and physical variables was performed with the support of SISVAR program (Ferreira, 2010). Volatile compound composition profile data were analyzed 
using a multivariate statistical analysis using the PCA and HCA techniques using the Sensomaker software, version 1.91 (Nunes \& Pinheiro, 2017).

\section{Results and discussion}

The fruit ripening process includes a series of biochemical steps, where the compounds within the fruit are catabolized or synthesized. For example, the degradation of chlorophyll and synthesis of the phenolic compounds results in color changes. The chemical characterization of the camu-camu (Table 1) throughout the development, detected significant $(\mathrm{p}<0.05)$ levels of vitamin $\mathrm{C}$ and total polyphenols, compounds with effective bioactive activity, besides influencing the metabolism of other secondary compounds such as volatiles. The increase observed in vitamin $c$ and polyphenols compounds antioxidant during the development of fruit demonstrate the capacity these fruit with source of nutrients with high aggregate value biologic, that can be important in your maintenance and utilization for food human nutrition. Observed that changes in polyphenols content are similar with the change in the volatile compounds during of development stages. The degradation and synthesis of new volatile compounds occur through the end of the physiological process. Silva et al. (2013) reports that volatile compounds are of great importance during the development process, because they facilitate the maintenance and perpetuation of the species. These compounds are responsible for the characteristic aroma and can be synthesized during development, post-harvest, and storage. The overall composition in the fruit is determined by several factors, such as the species, variety, and technological treatments used (Rizzolo et al., 1992).

For the color results, a significant increase was observed in all variables $\left(\mathrm{L}^{*}, \mathrm{a}^{*}\right.$ and $\mathrm{b}^{*}$ ) (Table 1 ), highlighting the values detected in $a^{\star}$ and $b^{*}$, which reflect the intensification of the red color (Figure 1), which may be correlated with carotenoid deboning and synthesis and chlorophyll degradation. These values may also be correlated with the results obtained for volatiles, since this variation is closely correlated with terpenoid synthesis. According to Yuan et al. (2015), tetraterpenes or carotenoids, are widely distributed pigments in nature, responsible for checking the coloration of different plants, vegetables and foods with a spectrum of colors ranging from yellow to red. Among the very important functions performed by this class of terpenes in nature

Table 1: Chemical composition of the camu-camu in three stages of maturation.

\begin{tabular}{|c|c|c|c|c|}
\hline Variables & & Green fruit & Mature green & Ripened \\
\hline $\mathrm{pH}$ & & $2.23 \mathrm{~b} \pm 0.31$ & $3.68 \mathrm{a} \pm 0.25$ & $2.41 \mathrm{~b} \pm 0.22$ \\
\hline At $(\mathrm{g}$ de citric acid.100g-1) & & $2.75 a \pm 0.21$ & $2.77 a \pm 0.12$ & $2.4 \mathrm{a} \pm 0.18$ \\
\hline SS ( ${ }^{\circ}$ Brix) & & $6.92 \mathrm{~b} \pm 0.82$ & $7.73 b \pm 0.52$ & $9.02 \mathrm{a} \pm 0.75$ \\
\hline Vitamin C (mg/100g ascorbic acid) & & $1230 \mathrm{~b} \pm 2.56$ & $1264 \mathrm{a} \pm 2.63$ & $1150 \mathrm{c} \pm 1.35$ \\
\hline Polyphenls Total (mg/100g gallic acid) & & $1380 \mathrm{a} \pm 2.72$ & $1352 \mathrm{a} \pm 1.61$ & $1280 \mathrm{~b} \pm 1.21$ \\
\hline \multirow[t]{3}{*}{ Colour values } & $\mathrm{L}^{*}$ & $63.83 \mathrm{a} \pm 3.2$ & $54.20 \mathrm{~b} \pm 2.35$ & $26.77 c \pm 1.52$ \\
\hline & $a^{*}$ & $8.56 \mathrm{c} \pm 1.23$ & $13.32 \mathrm{~b} \pm 1.36$ & $20.78 \mathrm{a} \pm 1.70$ \\
\hline & $b^{*}$ & $35.30 \mathrm{a} \pm 2.32$ & $25.36 \mathrm{~b} \pm 1.85$ & $6.79 c \pm 0.85$ \\
\hline
\end{tabular}

Means followed by the same letter in the line do not differ from each other $(\mathrm{p}<0.05)$.
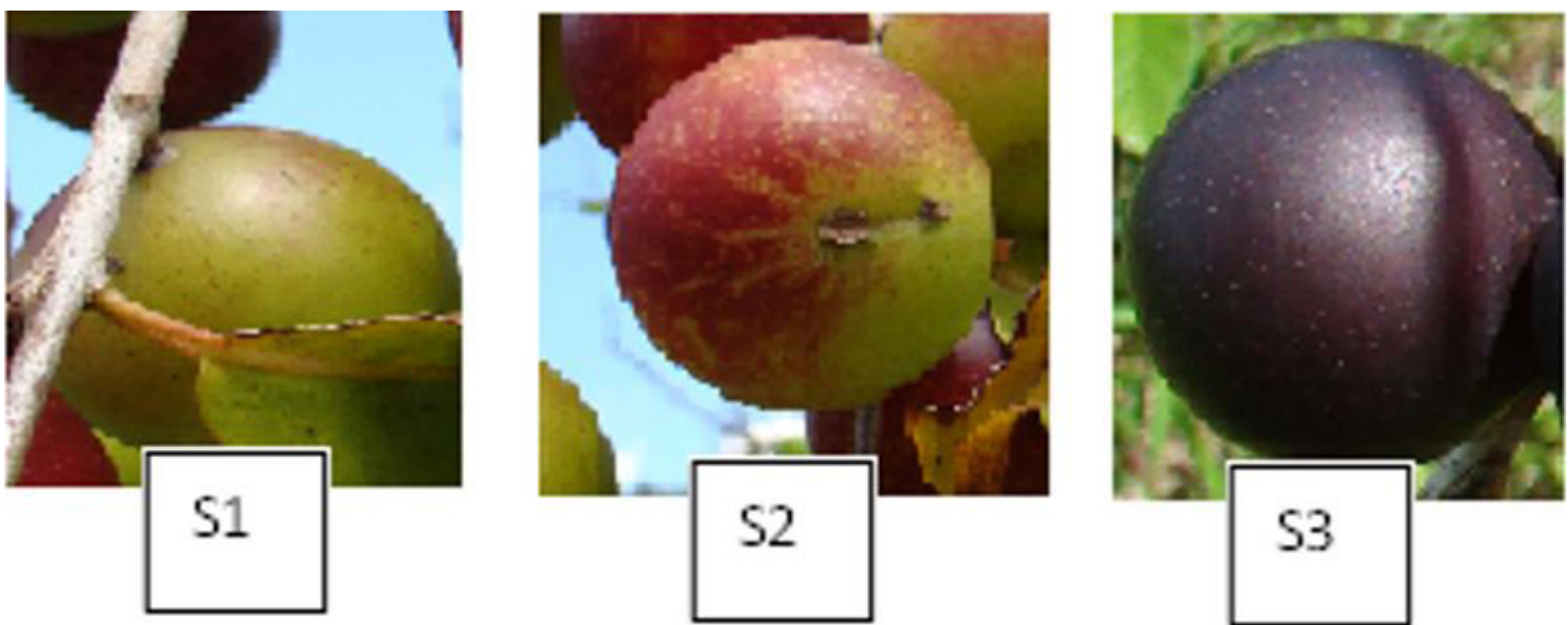

Figure 1. Camu-camu at different ripening stages. 1: Green camu-camu fruit; 2: camu-camu fruit beginning the ripening; 3: camu-camu fruit at intermediate stage of ripening; 
are: (i) are considered accessory pigments of photosynthesis in plants, presenting maximum absorption in the range of ultraviolet and blue; (ii) in animal tissues, some of them are precursors of vitamin A; (iii) certain carotenoids have significant antioxidant activity (Souza et al., 2013).

The results obtained in this study corroborate this difference, as the volatile compound composition of camu-camu changed in different phases of ripening, along with the color of the fruits (Table 2, Figure 2). A large percentage of volatile compounds was identified for fruits in the immature green stage $(90.9 \%$ were identified), the fruit stage mature green $(92.30 \%$ were identified), and the mature fruit ( $84.61 \%$ were identified).

The compounds were identified including hydrocarbons (heptane $6.11 \%$, decane $5.77 \%$ ), alcohols (Hepten-1-ol (4Z) 3.74\%), esters (Methyl butyl-2-methyl butyrate $<2->9.05 \%$ ), and terpenes (caryophyllene $31.02 \%$, tricyclene $14.02 \%$, limonene $10.01 \%$, sabinene $7.21 \%$, isocitrinellene $4.78 \%$, pinene $3.39 \%$ ); terpenes represented the highest percentage of volatile compounds (Figure 2, Table 2). Zhang et al. (2017) also found that terpenes were the major class of volatile compounds in different citrus species. In plants, monoterpenes exert a fungicidal role and attract pollinators (Chitarra \& Chitarra, 2005). The high content of terpenes, such as caryophyllene, which is a sesquiterpene compound found in the essential oils of many different species (Molina-Jasso et al., 2009), found in green fruit may also

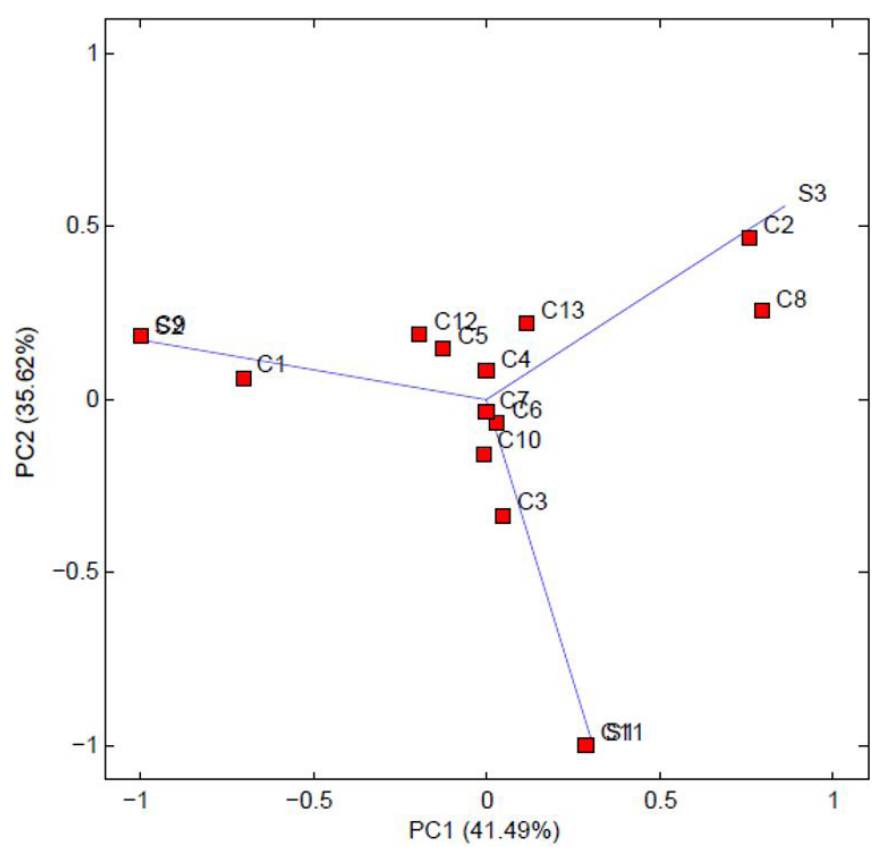

Figure 2. Principal component analysis (PCA) for the volatile profile of camu-camu fruit at different ripening stages. S1, S2 and S3. C: Identification of the compounds according to Table 2.

Table 2. Volatile compounds of the camu-camu in different ripening stages.

\begin{tabular}{|c|c|c|c|c|c|c|}
\hline \multirow{2}{*}{ ID } & \multirow{2}{*}{${ }^{\star}$ Compounds } & \multirow{2}{*}{${ }^{\star *} \mathrm{RI}$} & \multicolumn{3}{|c|}{ Stage (\% area) } & \multirow{2}{*}{$\frac{ \pm}{\text { Odors }^{* * *}}$} \\
\hline & & & S1 & S2 & S3 & \\
\hline 1 & Carene $\alpha-3$ & 1011 & 0 & 9.04 & 6.98 & Citrus \\
\hline 2 & Carophyllene-E- & 1419 & 31.02 & 5.98 & 6.15 & Citrus \\
\hline 3 & Cymene -p- & 1024 & 0 & 2.8 & 3.05 & Floral \\
\hline 4 & Decane (n) & 1000 & 5.77 & 0 & 0 & Fruit \\
\hline 5 & Isocitronellene & 923 & 4.78 & 0 & 0 & Fruit \\
\hline 6 & Heptane & 700 & 6.11 & 0 & 0 & Fruit \\
\hline 7 & Hepten-1-ol & 966 & 3.74 & 0 & 0 & Fruit \\
\hline 8 & Limonene & 1029 & 10.01 & 32.1 & 27.54 & Citrus \\
\hline 9 & Methyl-2-butyrate & 1100 & 9.05 & 0 & 0 & Fruit \\
\hline 10 & Myrcene & 990 & 0 & 3.2 & 4.56 & Spicy \\
\hline 11 & Pentanoic acid 4 methyl & 940 & 0 & 2.74 & 0 & Fruit \\
\hline 12 & Pinene $\beta$ & 979 & 3.39 & 4.96 & 3.75 & Fruit \\
\hline 13 & Phellandrene $\beta$ & 1029 & 0 & 2.73 & 0 & Fennel \\
\hline 14 & Sabinene & 975 & 7.21 & 0 & 0 & Citrus \\
\hline 15 & Sylvestrene - iso- & 1008 & 0 & 3.38 & 4.25 & Fruit \\
\hline 16 & Terpinen-4-ol & 1177 & 0 & 0 & 2.63 & Herbal \\
\hline 17 & Terpinene $\alpha$ & 1059 & 0 & 4.01 & 3.92 & Woddy \\
\hline 18 & Thujene- $\alpha-$ & 930 & 0 & 2.8 & 3.11 & Fruit \\
\hline 19 & Tricyclene & 926 & 14.2 & 23.26 & 28.35 & Green \\
\hline
\end{tabular}

S1, S2 and S3: stages green fruit, mature green and ripened respectively. ${ }^{\star}$ Identification of compounds according by bibliography Willey229.Lib, FFSC1.3.Lib and Adams, 2007. ${ }^{* *} \mathrm{RI}=$ retention index on DB-5 capillary column. ${ }^{* * *}$ (The Good Scents Company, 2019). 
be associated with the plant's defense system. In addition, caryophyllene is associated with anti-inflammatory activities, gastric cytoprotective effects, antioxidants, and other functions (Tambe et al., 1996). An increase in the concentration of tricyclene and limonene was observed during development; this increase was associated with the synthesis of phenolic compounds in the fruit. According to Aguiar et al. (2019), limonene is the major component of lemon and orange peel oils, as well as alkaline essential oils, and is effective in preventing dehydration and inhibiting microbial growth in plants.

Similar to the green fruit stage, terpenes were the dominant class of identified compounds (Figure 2, Table 2). However, a change was observed in the percentage of the major compounds; a significant increase was detected in tricyclene (from 14.2\% to $23.26 \%$ ) and limonene (from $10.01 \%$ to $32.1 \%$ ). A drastic reduction of caryophyllene, which was the major compound in the green fruit, was observed (from $31.02 \%$ to $5.98 \%$ ) in the fruit at this stage. These same compounds were detected by Caprioli et al. (2016), Kupska et al. (2014) and Dabbou et al. (2016) in Concomitant to these changes, there is an accentuation of the purple color in the fruits, a factor that may be related to the degradation of chlorophyll and synthesis of pigments. The route of formation of these compounds occurs via the mevalonate route and 1-deoxylylulose 5-phosphate (DXP) pathway, which give rise to the different terpenes (Kitaoka et al., 2015). According to Yuan et al. (2015), terpenes and carotenoids have a wide distribution in nature responsible for conferring the color and aroma of different plants, vegetables, and foods. The color spectrum ranges from yellow to red. There is an extensive variety of tetraterpenes, which are divided into carotenes (terpenes) and xanthophylls (terpenoids).

In the ripened fruits, peaks were identified, which represents a percentage of $84.61 \%$ (Figure 2, Table 2). Similar to the other stages of development, the terpene class predominated the volatile compounds; unlike the other stages of development, there was a significant increase in tricyclene, which increased from $14.2 \%$ in the immature green camu-camu to $23.26 \%$ mature green, reaching $28.35 \%$ in ripened camu-camu. A high limonene content of $27.54 \%$ was also observed. The high content of terpenoids detected with the advancement of ripening is directly related to the degradation of chlorophyll and synthesis of carotenoids, a class which comprises the terpenes and their homologs. Aguiar et al. (2019), evaluate the chemical and volatile composition of an Amazonian fruit, detected similar results in relation to terpenes as major compounds, with emphasis on alpha-pinene and limonene. Martineli et al. (2013), and Franco et al. (2004) also detected terpenes as the major class when analyzing the volatile compounds in persimmon and mango cultivars, respectively. Mono- and sesqui-terpenes, phenolic derivatives, lipid derived compounds, compounds derived from amino acids, and compounds derived from the breakdown of carotenoids, among others, are the most important compounds responsible for aroma (Lewinsohn et al., 2005). Kupska et al. (2014) observed a similar results in your studied about comprehensive two-dimensional gas chromatography for determination of the terpenes profile of berries. According to Edagi \& Kluge (2009), during the fruit ripening process, ethylene induces the formation of compounds responsible for the aroma of the fruit. According to Chitarra \& Chitarra (2005), in the post-harvest phase, the aroma changes based on the degree of maturation, harvest season, nutrition, handling, storage, and artificial maturing.

\section{Conclusion}

Terpenes were the dominate class of volatile compounds identified by HSPME-CG/MS in the maturation stages evaluated. In the immature green stage, the compound with the highest percentage of area was caryophyllene $31.02 \%$; in the mature green stage, limonene $32.01 \%$ had the highest percentage of area, and in the ripened stage, tricyclene $28.35 \%$ had the highest percentage of area. This identification provides important information for the food, flavor, and pharmaceutical industries, because these compounds have proven antioxidant and antimicrobial roles, demonstrating their viability in food, cosmetics, and perfumes. In the chemical composition, vitamin $\mathrm{C}$ contents and total polyphenols found in mature fruits

\section{Acknowledgements}

The authors are grateful for the financial support provided by CNPq, INMETRO, FAPEAM, BFN/FAO (Biodiversity Food Nutrition) and Agropecuária Jayoro Ltda. The authors declare that there is no conflict of interest

\section{References}

Adams, R. P. (2007). Identification of essential oil components by gas chromatography/mass spectrometry (p. 804). Carol Stream, USA: Allured Publishing Corporation.

Aguiar, J. P. L., Silva, E. P., Pereira, R. C. Jr., Nagahama, D., \& Souza, F. (2019). Aromatic and nutritional profile of an Amazonian autochthonous species, Caramuri Pouteria elegans (A.DC.) Baehni. International Journal of Food Properties, 22(1), 1242-1249. http:// dx.doi.org/10.1080/10942912.2019.1640248.

Association of Official Agricultural Chemists - AOAC. (2010). Official methods of the association of the agricultural chemists. Washington, DC: AOAC.

Caprioli, G., Iannarelli, R., Cianfaglione, K., Fiorini, D., Giuliani, C., Lucarini, D., Papa, F., Sagratini, G., Vittori, S., \& Maggi, F. (2016). Volatile profile, nutritional value and secretory structures of the berry-like fruits of Hypericum androsaemum L. F. Res. International., 79, 1-10. http://dx.doi.org/10.1016/j.foodres.2015.11.021.

Chitarra, M. I. F., \& Chitarra, A. B. (2005). Post-harvesting offruits and vegetables, physiology and handling (2nd ed., p. 783). Lavras: UFLA.

Cozzolino, R., De Magistris, L., Saggese, P., Stocchero, M., Martignetti, A., Di Stasio, M., Demyttenaere, J., \& Kimpe, N. (2001). Volatile Compounds. Journal of Molecular Catalysis. B, Enzymatic, 11, 265. http://dx.doi.org/10.1016/S1381-1177(00)00040-0.

Dabbou, S., Lussiana, C., Maatallah, S., Gasco, L., Hajlaoui, H., \& Flamini, G. (2016). Changes in biochemical compounds in flesh and peel from Prunus persica fruits grown in Tunisia during two maturation stages. Plant Physiology and Biochemistry, 100, 1-11. http://dx.doi.org/10.1016/j.plaphy.2015.12.015. PMid:26773475.

Edagi, F. K., \& Kluge, R. A. (2009). Persimmon astringency removal: A biochemical, physiological and technological approach. Ciência Rural, 39, 585-584. http://dx.doi.org/10.1590/S0103-84782009000200046. 
Franco, M. R. B., Rodriguez-Amaya, D., \& Lanças, F. M. (2004). Volatile compounds of three mango cultivars (Mangifera indica L.). Food Science and Technology, 24(2), 165-169.

Ferreira, D. F. (2010). Sisvar: sistema de análise de variância. Versão 5.3. Lavras: UFLA.

Janzantti, N. S., Macoris, M. S., Garruti, D. S., \& Monteiro, M. (2012). Influence of the cultivation system in the aroma of the volatile compounds and total antioxidant activity of passion fruit. Lebensmittel-Wissenschaft + Technologie, 46(2), 511-518. http:// dx.doi.org/10.1016/j.lwt.2011.11.016.

Kitaoka, N., Lu, X., Yang, B., \& Peters, R. J. (2015). The application of synthetic biology to elucidation of plant mono-, sesqui-, and diterpenoid metabolism. Molecular Plant, 8(1), 6-16. http://dx.doi. org/10.1016/j.molp.2014.12.002. PMid:25578268.

Knee, M. (2002). Fruit quality and its biological basis. Ohio: Ohio University, 265p.

Kupska, M., Chmiel, T., Jedrkiewicz, R., Wardencki, W., \& Namiesnik, J. (2014). Comprehensive two-dimensional gas chromatography for determination of the terpenes profile of blue honeysuckle berries. Food Chemistry, 152, 88-93. http://dx.doi.org/10.1016/j. foodchem.2013.11.129. PMid:24444910.

Lewinsohn, E., Sitrit, Y., Bar, E., Azulay, Y., Meir, A., Zamir, D., \& Tadmor, Y. (2005). Carotenoid pigmentation affects the volatile composition of tomato and watermelon fruits, as revealed by comparative genetic analyzes. Journal of Agricultural and Food Chemistry, 53(8), 31423148. http://dx.doi.org/10.1021/jf047927t. PMid:15826071.

Ma, Q., Hamid, N., Bekhit, A., Robertson, J., \& Law, T. (2013). Optimization of headspace solid phase microextraction (HS-SPME) for gas chromatography mass spectrometry (GC-MS) analysis of aroma compounds in cooked beef using response surface methodology. Microchemical Journal, 111, 16-24. http://dx.doi.org/10.1016/j. microc.2012.10.007.

Martineli, M., Ribeiro Alves, A., Machado de Figueiredo, G., Moraes de Rezende, C., \& de Oliveira Fonseca, M. (2013). 'Mikado': analysis of volatile compounds in astringent and destanizados fruits. Ciência Rural, 43, 1516-1521. http://dx.doi.org/10.1590/ S0103-84782013000800028.

Molina-Jasso, D., Álvarez-González, I., \& Madrigal-Bujaidar, E. (2009). Clastogenicity of beta-caryophyllene in mouse. Biological \& Pharmaceutical Bulletin, 32(3), 520-522. http://dx.doi.org/10.1248/ bpb.32.520. PMid:19252309.

Nunes, C., \& Pinheiro, A. C. M. (2017). SensoMaker, Version 1.91. Lavras: UFLA.
Pontes, M., Marques, J. C., \& Câmara, J. S. (2009). Headspace solid-phase microextraction-gas chromatography-quadrupole mass spectrometric methodology for the establishment of the volatile composition of Passiflora fruit species. Microchemical Journal, 93(1), 1-11. http:// dx.doi.org/10.1016/j.microc.2009.03.010.

Rizzolo, A., Polesello, A., \& Polesello, S. (1992). Use of headspace capillary GC to study the development of volatile compounds in fresh fruits. Journal of High Resolution Chromatography, 15(7), 472-477. http:// dx.doi.org/10.1002/jhrc.1240150713.

Rodríguez, A., San Andrés, V., Cervera, M., Redondo, A., Alquézar, B., Shimada, T., Gadea, J., Rodrigo, M. J., Zacarías, L., Palou, L., López, M. M., Castañera, P., \& Peña, L (2011). Terpene down-regulation in orange reveals the role of fruit aromas in mediating interactions with insect herbivores and pathogens. Plant Physiology, 156(2), 793-802. http://dx.doi.org/10.1104/pp.111.176545. PMid:21525333.

Silva, E. P., Vilas Boas, E. V. B., \& Xisto, A. L. P. R. (2013). Characterization and development of marolo (Annona crassiflora, Mart). Food Science and Technology, 33(4), 666-675. http://dx.doi.org/10.1590/S010120612013000400011.

Simões, C. M. O. (2003). Pharmacognosy: from the plant to the medicine (5th ed., p. 495). Porto Alegre: UFRGS.

Souza, F. V. M., Rocha, M. B., Souza, D. P., \& Marçal, R. M. (2013). (-)-Carvone: antispasmodic effect and mode of action. Fitoterapia, 85, 20-24. http://dx.doi.org/10.1016/j.fitote.2012.10.012. PMid:23103297.

Tambe, Y., Tsujiuchi, H., Honda, G., Ikeshiro, Y., \& Tanaka, S. (1996). Gastric cytoprotection of the non-steroidal anti-inflammatory sesquiterpene, -caryophyllene. Planta Medica, 62(5), 469-470. http:// dx.doi.org/10.1055/s-2006-957942. PMid:9005452.

The Good Scents Company (2019). TGSC Information System. Retrieved from http://www.thegoodscentscompany.com/search2.html.

Yuan, H., Zhang, J., Nageswaran, D., \& Li, L. (2015). Carotenoid metabolism and regulation in horticultural crops. Nature Review: Horticulture Research, 2(1), 11-15. http://dx.doi.org/10.1038/ hortres.2015.36. PMid:26504578.

Yuyama, K., Aguiar, J. P. L., \& Yuyama, L. K. O. (2002). Camu-camu: a fantastic fruit as a source of vitamin C1. Acta Amazonica, 32, 169174. http://dx.doi.org/10.1590/1809-43922002321174. [[Q8: Q8]]

Zanatta, C. F., \& Mercadante, A. (2007). Composition from the Brazilian tropical fruit camu-camu (Myrciaria dubia). Food Chemistry, 101(4), 1526-1532. http://dx.doi.org/10.1016/j.foodchem.2006.04.004.

Zhang, H., Xie, Y., Liu, C., Chen, S., Hu, S., Xie, Z., Deng, X., \& Xu, J. (2017). Comprehensive comparative analysis of volatile compounds in citrus fruits of different species. Food Chemistry, 230, 316-326. http://dx.doi.org/10.1016/j.foodchem.2017.03.040. PMid:28407917. 